\title{
Plant Growth Promotion Activity of Keratinolytic Fungi Growing on a Recalcitrant Waste Known as "Hair Waste"
}

\author{
Ivana A. Cavello, ${ }^{1}$ Juan M. Crespo, ${ }^{1}$ Sabrina S. García, ${ }^{1}$ José M. Zapiola, \\ María F. Luna, ${ }^{1,3}$ and Sebastián F. Cavalitto ${ }^{1}$ \\ ${ }^{1}$ Research and Development Center for Industrial Fermentations (CINDEFI), CONICET La Plata-UNLP, Calle 47 y 115, \\ B1900ASH La Plata, Argentina \\ ${ }^{2}$ Instituto de Microbiología y Zoología Agrícola, INTA, Nicolás Repetto y De Los Reseros s/n, CP 1686, Hurlingham, \\ Buenos Aires, Argentina \\ ${ }^{3}$ Comisión de Investigaciones Científicas de la Provincia de Buenos Aires (CIC-PBA), La Plata, Argentina
}

Correspondence should be addressed to Sebastián F. Cavalitto; cavali@biotec.org.ar

Received 14 July 2015; Revised 14 October 2015; Accepted 8 November 2015

Academic Editor: Rima Menassa

Copyright (C) 2015 Ivana A. Cavello et al. This is an open access article distributed under the Creative Commons Attribution License, which permits unrestricted use, distribution, and reproduction in any medium, provided the original work is properly cited.

Purpureocillium lilacinum (Thom) Samsom is one of the most studied fungi in the control of plant parasitic nematodes. However, there is not specific information on its ability to inhibit some pathogenic bacteria, fungi, or yeast. This work reports the production of several antifungal hydrolytic enzymes by a strain of $P$. lilacinum when it is grown in a medium containing hair waste. The growth of several plant-pathogenic fungi, Alternaria alternata, Aspergillus niger, and Fusarium culmorum, was considerably affected by the presence of $P$. lilacinum's supernatant. Besides antifungal activity, P. lilacinum demonstrates the capability to produce indoleacetic acid and ammonia during time cultivation on hair waste medium. Plant growth-promoting activity by cell-free supernatant was evidenced through the increase of the percentage of tomato seed germination from 71 to $85 \%$ after 48 hours. A 21 -day plant growth assay using tomato plants indicates that crude supernatant promotes the growth of the plants similar to a reference fertilizer $(p>$ 0.05). These results suggest that both strain and the supernatant may have potential to be considered as a potent biocontrol agent with multiple plant growth-promoting properties. To our knowledge, this is the first report on the antifungal, IAA production and tomato growth enhancing compounds produced by P. lilacinum LPSC \#876.

\section{Introduction}

Keratin solid wastes are globally recognized as a crucial industrial waste because of the amount produced every year and the environmental problems that they represent due to their limited use and the consequent need of disposal. Argentina's economy is strongly based on agriculture related industries. There are around 50 million livestock and more than 200 tanneries that process about 16 million bovine hides per year. Although hair-saving unhairing processes reduce the organic (COD) load from beamhouse liquid effluent, a new solid residue called "hair waste" is generated, being then necessary for its appropriate disposal. The amount of hair recovered from a bovine hide after this process is about 3\% (dry weight based). Therefore, it was estimated that a tannery, processing 25 ton of salted hides per day, produces about 2.5 ton of wet hair $(70 \%$ moisture) $[1,2]$. Nowadays, after the processing of bovine hides, hair wastes are disposed to landfills carrying potent polluting implications.

The main component of hair waste is keratin, a fibrous and insoluble structural protein rich in $\beta$-helical coils linked through disulfide bridges which render to this protein the resistance to degradation by common proteases like pepsin, papain, and trypsin [3]. Considering its high protein content, this kind of waste could have a great potential. The biotransformation of hair waste could give rise to a partially degraded organic material with high nitrogen content due to extent of the proteolysis when microorganisms act. This new biomaterial could have different potential uses, that is, as a highly digestible protein source for animal feeding, 
as a raw material in the fertilizing or chemical industry, and as substrate for the production of enzymes such as proteases and keratinases $[2,4,5]$.

Although several potential applications are proposed for the utilization of this kind of recalcitrant wastes, the simplest and most appropriate use is as fertilizers, being necessary for the isolation and characterization of keratin-degrading microorganisms not only with keratinolytic activity but also with plant growth-promoting activity [6, 6-9]. From an agrobiochemical point of view, keratinolytic microorganism, which is able to produce antifungal and plant growth-promoting activities, could offer a number of economic and environmental advantages over chemical-based control applications [10].

The aim of this work was to study plant growth-promoting activity of the keratinolytic fungus Purpureocillium lilacinum LPSC \#876. This fungus is able to produce proteases, keratinases, laminarases, and chitinases enzymes simultaneously under submerged fermentation using hair waste as substrate. It also produces one of the most physiologically active auxins, indoleacetic acid (IAA), and presents several antifungal activities, which turn P. lilacinum culture supernatant into a promising candidate for the development of an organic biofertilizer with biological control.

To our knowledge, this is the first report on the antifungal activity, phytohormones production, and plant growth enhancement by P. lilacinum LPSC \#876.

\section{Materials and Methods}

2.1. Chemicals. Laminarin, chitin, N-acetylglucosamine, ND-galacturonic acid monohydrate (GALA), polygalacturonic acid (PGA) from citrus fruits, and carboxymethylcellulose (CMC) were purchased from Sigma Chemical Co., St. Louis, MO. All other chemicals were commercially available and were of analytical grade.

2.2. Microorganism, Inoculum Preparation, and Culture Conditions. Purpureocillium lilacinum LPSC \#876 (formerly Paecilomyces lilacinus), isolated from soils in public places from La Plata, Argentina [11], is a nonpathogenic fungal strain, which is deposited at the Spegazzini Institute fungal culture collection (La Plata National University, Argentina).

P. lilacinum was streaked on Potato Dextrose Agar dishes and incubated at $28^{\circ} \mathrm{C}$ for 10 days. After this period of time, spores were harvested by flooding the agar dish with $10 \mathrm{~mL}$ of $0.05 \%$ Tween 80 sterile solution and gently stirring the surface with a sterile magnetic bar. Concentration of spore suspension was determined in a Neubauer chamber [12].

Cultures were established in 1,000 mL Erlenmeyer flasks in $200 \mathrm{~mL}$ of hair medium containing (per liter) $10 \mathrm{~g}$ hair waste, $0.496 \mathrm{~g} \mathrm{NaH} \mathrm{PO}_{4}, 2.486 \mathrm{~g} \mathrm{~K} \mathrm{HPO}_{4}, 0.0016 \mathrm{~g}$ $\mathrm{FeCl}_{3} \cdot 6 \mathrm{H}_{2} \mathrm{O}, 0.0013 \mathrm{~g} \mathrm{ZnCl}_{2}, 0.0010 \mathrm{~g} \mathrm{MgCl}_{2}$, y $0.0065 \mathrm{mg}$ $\mathrm{CaCl}_{2}$, and $7.10 \mathrm{~g}$ glucose ( $\mathrm{pH}$ 5.6) [13]. Hair waste, obtained from a local tannery, was extensively washed with tap water, dried at $60^{\circ} \mathrm{C}$ for 2 days, and kept at room temperature until used. The culture flasks were autoclaved at $121^{\circ} \mathrm{C}$ for $15 \mathrm{~min}$ for sterilization and then, after cooling, inoculated with $2 \times 10^{6}$ conidia per $\mathrm{mL}$. The cultures were incubated in an orbital shaker at $200 \mathrm{rpm}$ and $28^{\circ} \mathrm{C}$. After 6 days of cultivation, the culture was withdrawn and centrifuged $(5,000 \times \mathrm{g}, 10 \mathrm{~min}$, $4^{\circ} \mathrm{C}$ ), and the supernatant was then used to test some in vitro and in vivo activities involved in plant growth promotion and biological control.

\subsection{In Vitro Screening of P. lilacinum for Its Plant Growth-Promoting and Antifungal Activities}

2.3.1. Assay for Indoleacetic Acid (IAA) Production. Production of IAA was investigated in optimal hair waste medium with different concentration of L-tryptophan $(0 \%, 0.02 \%$, and $0.1 \%)$. Cultures were performed as was described above and samples were withdrawn every regular period of time and IAA was estimated by mixing $1 \mathrm{~mL}$ of Salkowski reagent with $1 \mathrm{~mL}$ of culture supernatant followed by measuring absorbance at $530 \mathrm{~nm}$ after $30 \mathrm{~min}$ of incubation at room temperature. IAA from Sigma was used as standard [14].

2.3.2. Phosphate Solubilization by P. lilacinum. Phosphate solubilization was investigated in NBRIP (National Botanical Research Institute's phosphate) growth medium containing $0.5 \%(\mathrm{w} / \mathrm{v}) \mathrm{Ca}_{3}\left(\mathrm{PO}_{4}\right)_{2}$ as the insoluble phosphate source [10]. Solubilization of phosphate by the microorganism was demonstrated by the production of a halo around the colony.

2.3.3. $\mathrm{NH}_{3}$ Production. The production of ammonia due to fungal degradation of hair waste was determined according to the method of Chaney and Marbach using $\mathrm{NH}_{4}\left(\mathrm{SO}_{4}\right)_{2}$ as standard [15].

2.3.4. Determination of Cell Wall-Degrading Enzymes Activities. $\beta-1,3-G l u c a n a s e$ (laminarase) activity was measured using laminarin (SIGMA) as substrate. The admixture containing $180 \mu \mathrm{L}$ of $1 \%$ laminarin in $12.5 \mathrm{mM}$ citric acid/ $6.25 \mathrm{mM} \mathrm{Na}_{2} \mathrm{HPO}_{4}$ buffer (CPB, pH 5.0) and $20 \mu \mathrm{L}$ of the enzyme preparation was incubated at $37^{\circ} \mathrm{C}$ for $2 \mathrm{~h}$ [16]. After incubation, the released reducing sugars were determined at $660 \mathrm{~nm}$ according to Nelson-Somogyi method using glucose as standard $[17,18]$. One unit of laminarase activity was defined as the amount of enzyme that catalyzed the release of one micromole of glucose per hour under experimental conditions.

For chitinase activity determination, the admixture containing $450 \mu \mathrm{L}$ of $1 \%$ sieved chitin $(500 \mu \mathrm{m}>\varnothing>100 \mu \mathrm{m})$ in $\mathrm{CPB}(12.5 \mathrm{mM}$; $6.25 \mathrm{mM}$, pH 5.0) and $50 \mu \mathrm{L}$ of culture supernatants was incubated at $37^{\circ} \mathrm{C}$ for $24 \mathrm{~h}$ [19]. The release of reducing sugars was quantified by Nelson-Somogyi method using N-acetyl-D-glucosamine (NAG) as standard. One unit of chitinase activity was defined as the amount of enzyme that releases a reducing power equivalent to one nanomole of NAG per hour under those experimental conditions.

Polygalacturonase activity was determined using polygalacturonic acid as substrate. The reaction mixture containing $180 \mu \mathrm{L}$ of $0.20 \%$ polygalacturonic acid dissolved in CPB (12.5 mM; 6.25 mM, pH 5.0) and $20 \mu \mathrm{L}$ of the culture supernatants was incubated at $37^{\circ} \mathrm{C}$ for $24 \mathrm{~h}$ [20]. The release 
of reducing sugars was quantified by measuring the rate of increase of galacturonic acid concentrations using NelsonSomogyi method. One unit of enzyme activity was defined as the amount of enzyme that catalyzed the release of one micromole of galacturonic acid per hour under the given assay conditions.

Carboxymethyl cellulase activity was measured using carboxymethyl cellulose as substrate. The reaction mixture containing $180 \mu \mathrm{L}$ of $1.0 \%$ of carboxymethyl cellulose dissolved in CPB (12.5 mM; $6.25 \mathrm{mM}$, pH 5.0) and $20 \mu \mathrm{L}$ of the culture supernatants was incubated at $37^{\circ} \mathrm{C}$ for $24 \mathrm{~h}$ [20]. The release of reducing sugars was quantified by measuring the rate of increase of glucose concentrations using Nelson-Somogyi method $[17,18]$. One unit of cellulose activity was defined as the amount of enzyme that catalyzed the release of one micromole of glucose per hour under the given assay conditions.

\subsubsection{Antifungal Assays}

(1) Antagonistic Properties of P. lilacinum LPSC \#876. A dual culture technique was performed in order to test the ability of $P$. lilacinum to inhibit the growth of several plant-pathogenic fungi (Alternaria alternata \#25031, Aspergillus niger AKU 3302, Fusarium culmorum \#29, F. graminearum FUSKU \#117, and F. graminearum \#206). Plant-pathogenic fungi were grown on potato dextrose agar (PDA, Oxoid) for 10 days at $28^{\circ} \mathrm{C}$ and then stored at $4^{\circ} \mathrm{C}$ until used. A $5 \mathrm{~mm}$ diameter agar plug containing each fungal mycelium was placed in front of $P$. lilacinum agar plug on PDA surface plates and incubated at $28^{\circ} \mathrm{C}$ for 5 days. After the plates were incubated, the inhibition of fungal growth was observed around P. lilacinum colony. Control plates were prepared by growing each fungus tested in absence of $P$. lilacinum. Dual culture technique for each plant-pathogenic fungus was performed by quintuplicate.

(2) Antagonist Properties of Cell-Free Supernatant. Supernatant antifungal activity was estimated via a growth inhibition assay as follows: double concentration PDA was prepared and sterilized and allowed cooling up to $50^{\circ} \mathrm{C}$. Two groups of plates were prepared by quintuplicate. In the experimental $(E)$ group, equal amounts of concentrated PDA and filtrate sterilized culture supernatant were mixed and poured. In the control $(C)$ group, the supernatant was replaced by sterilized distilled water. After plate cooling, a fungal disc $(5 \mathrm{~mm})$ of each pathogen was placed on the agar surface. Both groups were incubated at $25^{\circ} \mathrm{C}$ for $72 \mathrm{~h}$. The diameters of the fungal colonies were recorded twice a day and the averages calculated. For each pathogenic fungus, the colony radial growth rate was estimated from the slope of the linear regression of the colony diameter $(\mathrm{cm})$ on time $(\mathrm{h})$. The percentage of growth inhibition produced by the supernatant was calculated as follows [21]:

$$
\text { Inhibition ratio }(\%)=\frac{(C-E)}{C} * 100 \% \text {, }
$$

where $C$ is the average diameter of the colonies of the control groups and $E$ is the average diameter of the colonies of the experimental groups.
If the inhibition ratio exceeded $20 \%$, the tested fungus was considered inhibited [22].

\subsection{In Vivo Plant Growth Promotion Assays}

2.4.1. Seed Germination Assay. The ability of P. lilacinum to promote seedling growth was studied using cell-free supernatant according to Rajkumar and Freitas protocol with slight modifications [23]. Tomato seeds were surface-disinfected with sodium hypochlorite $(1.0 \% \mathrm{v} / \mathrm{v})$ for 10 minutes and washed with sterile distilled water. Equal numbers of seeds ( 350) were incubated with $100 \mathrm{~mL}$ of sterilized culture supernatant or distilled water, respectively, for $1 \mathrm{~h}$ at room temperature. One hundred seeds of each treatment were placed in sterile $0.8 \%$ agar plates and incubated at $28^{\circ} \mathrm{C}$ in the dark. All the treatments were made in triplicate. Visual assessments of seed germination were done daily up to 3 days. Every day, the number of seeds germinated was recorded and the percentage of germination calculated for each treatment. Univariate analysis of variance (ANOVA) was employed on each treatment and tested for its significance using Tukey's Student Range Test $\left(\mathrm{HSD}_{(0.05)}\right)$.

2.4.2. Effect on the Growth of Tomato (Lycopersicum esculentum cv. "Superman," Seminis) Plants. In order to evaluate the biofertilizer capacity of P. lilacinum on tomato growth, cellfree culture supernatant was used to irrigate tomato plants. Water and Fähraeus solution (supplemented with nitrogen, $0,5 \mathrm{~g} / \mathrm{L} \mathrm{NO}_{3} \mathrm{~K}$ ) were used as negative and positive control, respectively. Tomato seeds were screened by shape, color, and appearance in order to eliminate bad ones. They were surface-disinfected with $70 \%$ ethanol for $5 \mathrm{~min}$ and washed (once) with sterile water. Finally, they were immersed in $1.0 \%$ sodium hypochlorite for $10 \mathrm{~min}$ followed by three washes with sterile water. Seeds were germinated for 4 days at $28^{\circ} \mathrm{C}$ in the dark on semisolid medium ( $0.5 \%$ agar). Then, germinated seeds were placed in pots with sterile vermiculite as soilless potting media. Four germinated seeds were sown at a suitable depth in all pots, and the pots were placed on a greenhouse at $25^{\circ} \mathrm{C}$ with a $18 / 6 \mathrm{~h}$ photoperiod. During the experiment, each pot was irrigated with water, Fähraeus solution, or culture supernatant 3 times over a period of 15 days. After day 15, all pots were irrigated with distilled water. After 21 days, the plants were carefully removed from the pots and the root surface was cleaned several times with distilled water. Growth parameters such as fresh and dry weight of roots and shoots were recorded [23]. Univariate analysis of variance (ANOVA) was employed on each treatment and tested for its significance using Tukey's Student Range Test $\left(\mathrm{HSD}_{(0.05)}\right)$.

2.5. Experimental Design and Data Analysis. Enzymatic assays and IAA assays were conducted in triplicate and in Completed Randomized Design (CRD). The data were expressed as means \pm standard deviations. When it was necessary, results were analyzed by the Design Expert (Stat-Easy, Minneapolis, MN, USA) version 8.0.7.1. trial version software using univariate analysis of variance (ANOVA). Means were compared with Tukey's Student Range Test $\left(\mathrm{HSD}_{(0.05)}\right)$. 
TABLE 1: IAA production of several reported plant growth-promoting microorganisms.

\begin{tabular}{lccc}
\hline Microorganism & Tryptophan concentration (\% w/v) & IAA $(\mu \mathrm{g} / \mathrm{mL})$ & Reference \\
\hline P. lilacinum LPSC \#876 & 0.1 & 3.24 & \\
Gluconacetobacter diazotrophicus UAP 5701 & 0.01 & 1.07 & Fuentes-Ramirez et al. (1993) [46] \\
G. diazotrophicus UAP 7308 & 0.01 & 1.12 & Fuentes-Ramirez et al. (1993) [46] \\
Azospirillum brasilense CBG & 0.1 & 0.75 & Hernández-Mendoza et al. (2008) [47] \\
G. diazotrophicus 4-02 & 0.01 & 1.8 & Rodríguez Cheang et al. (2005) [48] \\
G. diazotrophicus PAl-5 & 0.01 & 2.2 & Rodríguez Cheang et al. (2005) [48] \\
Pseudomonas fluorescens AK-1 & 0.01 & 4.0 & Karnwal (2009) [49] \\
Bacillus cereus TS1 & 0.04 & 2.12 & Sivakumar et al. (2012) [45] \\
A. diazotrophicus L1 & 0.02 & 1.51 & Patil et al. (2011) [50] \\
\hline
\end{tabular}

\section{Results and Discussion}

The practical employment of keratinase-producing microorganisms is currently being explored within the context of bioconversion for the utilization of keratin wastes at room temperature [24]. These organisms have potential biotechnological applications and could replace the chemical processing used to convert these wastes into useful products. $P$. lilacinum LPS \#876 was previously reported as a keratinolytic fungus capable of producing keratinases when hair waste was used as substrate under submerged fermentation. Keratinases of $P$. lilacinum could be used for several purposes as it was stated early $[2,5,12]$. This report describes experiments that suggest that $P$. lilacinum LPS \#876 is able to produce a cell-free supernatant that can be considered as a multifunctional crude extract with keratinolytic, antifungal, and plant growthpromoting activities.

\subsection{In Vitro Screening of P. lilacinum for Its Plant \\ Growth-Promoting and Antifungal Activities}

3.1.1. Indole Acetic Acid Production by P. lilacinum in Optimal Hair Medium. The capability to synthesize IAA is an important feature for a strain to be considered as a plant growth-promoting agent; it is well known that this hormone participates in promotion of plant growth by increasing radical surface of inoculated plants [25]. IAA production was investigated using different concentration of L-tryptophan. Figure 1 shows that the production of IAA increases as long as the concentration of the precursor increases up to $0.1 \%$. Maximum production of IAA $(3.24 \pm 0.1 \mu \mathrm{g} / \mathrm{mL})$ was observed after 4 days of cultivation. Even without Ltryptophan supplementation, $P$. lilacinum was able to produce detectable amounts of IAA, probably due to hair degradation into free soluble amino acids.

Although the concentration of IAA reached by P. lilacinum is lesser than the concentration of IAA reached by the keratinolytic bacteria reported by Jeong et al. [8] (114.6 \pm $4.8 \mu \mathrm{g} / \mathrm{mL}$ ), it is in concordance with those reported for several plant growth-promoting bacteria (PGPB) including the keratinolytic bacteria Bacillus cereus TS1 (Table 1). Low levels of IAA can stimulate root elongation, while high levels can stimulate the formation of lateral and adventitious roots [26].

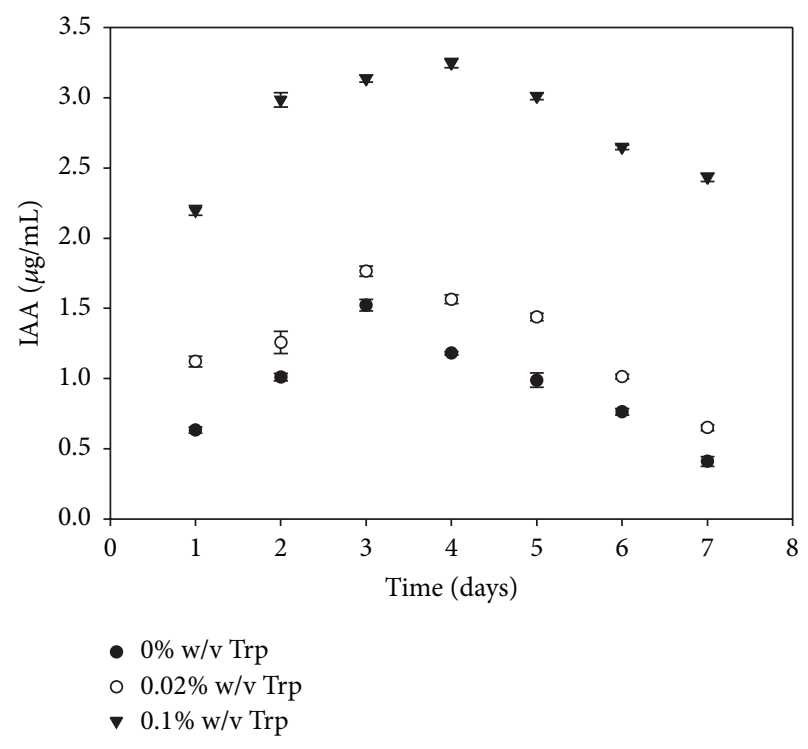

FIgURe 1: Production of indoleacetic acid by P. lilacinum under submerged fermentation containing various concentrations of Ltryptophan. Errors bars $( \pm$ S.D) are shown when larger than the symbol.

3.1.2. Phosphate Solubilization and Ammonia Production. P. lilacinum could not solubilize insoluble phosphates such as $\mathrm{Ca}_{3}\left(\mathrm{PO}_{4}\right)_{2}$. As can be seen in Figure 2, during time course of cultivation P. lilacinum produces ammonia due to protein degradation, reaching up to $300 \mathrm{ppm}$ after 6 days of cultivation.

3.1.3. Cell Wall-Degrading Enzymes Present in the Culture Supernatant. Among activities tested, culture supernatant of $P$. lilacinum exhibited hydrolyzing activities on laminarin $\left(3.4 \mathrm{U} \mathrm{mL}^{-1}\right)$ and chitin $\left(68.1 \mathrm{U} \mathrm{mL}^{-1}\right)$; however, nonenzymatic activities against PGA and CMC were detected (Table 2).

Purpureocillium lilacinum species are known to be good sources of degradative enzymes such as proteases, keratinases, and chitinases, being the first report of laminarases production by this strain [27-29]. These enzymes provide 
TABLE 2: Enzymes activities shown by culture supernatant of $P$. lilacinum LPSC \#876 using various substrates.

\begin{tabular}{|c|c|c|c|}
\hline Enzymes & Substrates & Concentration (w/v) & Enzyme activity $\left(\mathrm{UmL}^{-1}\right)$ \\
\hline Laminarase & Laminarin & $1.0 \%$ & $3.4 \pm 0.2$ \\
\hline Chitinase & Chitin & $1.0 \%$ & $68.1 \pm 0.3$ \\
\hline Polygalacturonase & Polygalacturonic acid & $0.2 \%$ & nd \\
\hline Cellulase & CM-cellulose & $1.0 \%$ & nd \\
\hline
\end{tabular}

n.d.: not detectable.

TABLE 3: Antagonistic effect of $P$. lilacinum supernatant on growth rate and percentage of mycelial growth inhibition of several phytopathogens.

\begin{tabular}{|c|c|c|c|}
\hline Phytopathogen & Growth rate $\left(\mathrm{cmday}^{-1}\right)$ & Growth rate in presence of $P$. lilacinum supernatant $\left(\mathrm{cmday}^{-1}\right)$ & Inhibition rate $(\%)$ \\
\hline A. alternata \#25031 & $1.20 \pm 0.08$ & $0.50 \pm 0.01$ & 57.0 \\
\hline A. niger & $1.16 \pm 0.02$ & $1.03 \pm 0.01$ & 27.0 \\
\hline F. culmorum $\# 29$ & $1.80 \pm 0.05$ & $1.30 \pm 0.01$ & 34.0 \\
\hline F. graminearum FUSKU \#117 & $0.80 \pm 0.04$ & $0.80 \pm 0.04$ & - \\
\hline F. graminearum \#206 & $1.30 \pm 0.07$ & $1.10 \pm 0.02$ & 27.0 \\
\hline
\end{tabular}

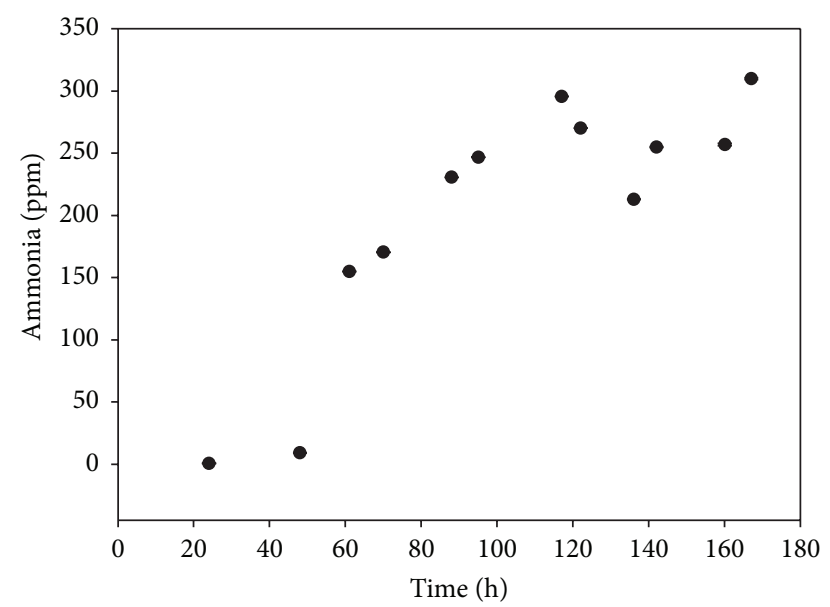

Figure 2: Time course of ammonia production by P. lilacinum under submerged fermentation.

a remarkable metabolic versatility, enabling the fungus to grow on a wide variety of substrates.

Recent reports have demonstrated that exposure of certain fungal hydrolyzing enzymes such as chitinases, proteases, cellulases, and glucanases to certain fungi resulted in the degradation of most fungal cell walls, the production of these enzymes being an important mechanism of fungal growth inhibition [16, 20, 30, 31]. Jeong et al. [8] have extensively worked with keratinolytic bacteria and their plant growth promotion activities. Among cell wall-degrading enzymes studied, they report the production of amylases, cellulases, pectinases, lipases, and proteases on Petri dishbased assays by keratinolytic bacteria Bacillus subtilis S8, Xanthomonas sp. P5, and Stenotrophomonas maltophilia R13.

3.1.4. Antagonistic Properties of P. lilacinum LPSC \#876. Purpureocillium lilacinum (Thom) Samsom is one of the most studied fungi, used in the control of plant parasitic nematodes. Under greenhouse and field conditions, it has been found infecting $50-100 \%$ of plant parasitic nematodes such as Meloidogyne incognita [32, 33], M. javanica [34], and Heterodera avenae Wollenweber [35], Radopholus similis [36], and Rotylenchulus reniformis [37]. However, there is not specific information on its ability to inhibit some pathogenic bacteria, fungi, or yeast. In the present study, $P$. lilacinum LPSC \#876 was screened for antifungal activity in vitro against some phytopathogenic fungi using dual culture assay on PDA plates. As can be seen in Figures 3(a)-3(e), P. lilacinum showed a wide range of antifungal activity against $A$. alternata, A. niger, F. culmorum, and F. graminearum \#206 but could not control the growth of F. graminearum FUSKU \#117.

According to Porter, P. lilacinum exhibits inhibition type C. In this type of inhibition, the space between the two colonies, while very narrow, is clearly marked [38].

3.1.5. Antagonism Properties of Culture Supernatant. Culture supernatant antifungal activity against selected soil-borne phytopathogens was estimated via a growth inhibition assay. In Table 3 and Figures 3 and 4, the growth rate of each fungus in absence and presence of culture supernatant as well as the inhibition ratio (\%) is shown. Except for F. graminearum FUSKU \#117, all other pathogenic strains were controlled by cell-free supernatant with inhibition ratios higher than $25 \%$.

The antagonistic phenomena against fungi can be explained by several mechanisms, including antibiosis and parasitism. In some cases, hydrolytic enzymes such as chitinases, glucanases, or proteases may act against the fungal cell wall [39]. Stefanova et al. [40] used filtrates from liquid cultures of several isolates of Trichoderma sp. Some of these isolates produce nonvolatiles metabolites with antifungal activity which reduce Phytophthora nicotianae and Rhizoctonia solani growth. Gousterova et al. [41] obtained a proteinrich hydrolysate from feather waste using a mixed culture of thermophilic actinomycete strains which was tested for antifungal activity against some common plant-pathogenic fungi (Fusarium solani, F. oxysporum, Mucor sp., and Aspergillus niger). Meanwhile, Mishra et al. [42] reported the effect of 


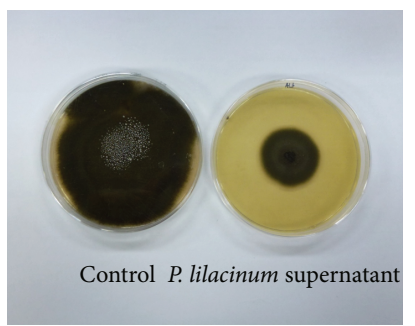

(i)

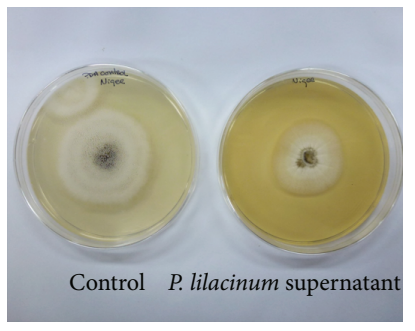

(i)

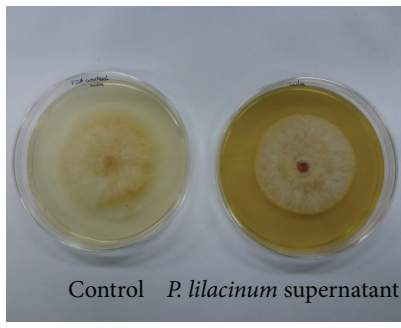

(i)

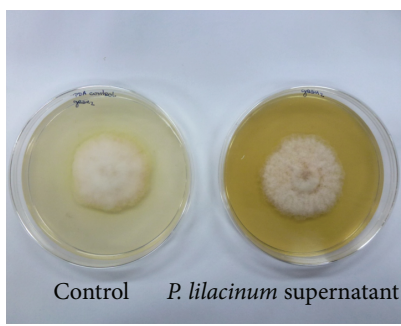

(i)

(a)

(b)

(c)

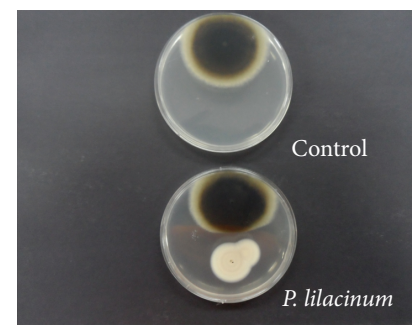

(ii)

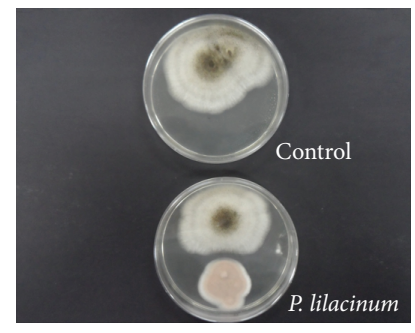

(ii)

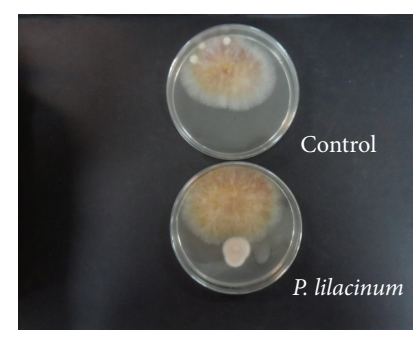

(ii)

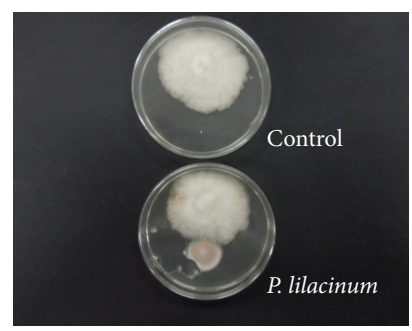

(ii)

(d)

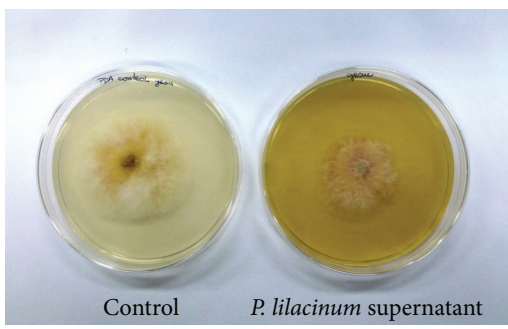

(i)

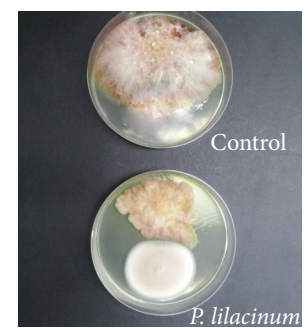

(ii)

(e)

FIGURE 3: Antifungal activity against fungal phytopathogens: (a) Alternaria alternata, (b) Aspergillus niger, (c) Fusarium culmorum, (d) Fusarium graminearum FUSKU \#177, and (e) F. graminearum \#206. (i) Supernatant antifungal activity and (ii) dual culture technique. 


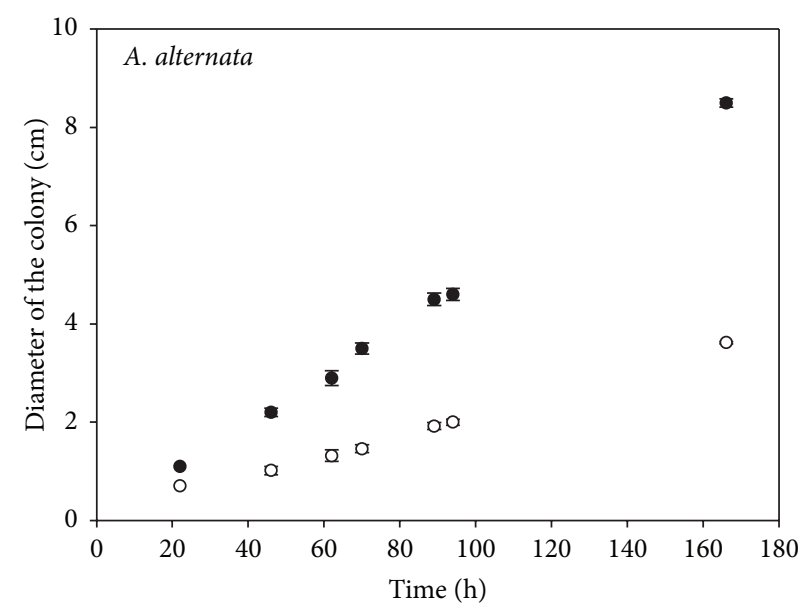

- Diameter of the colony

○ Diameter of the colony in presence of supernatant

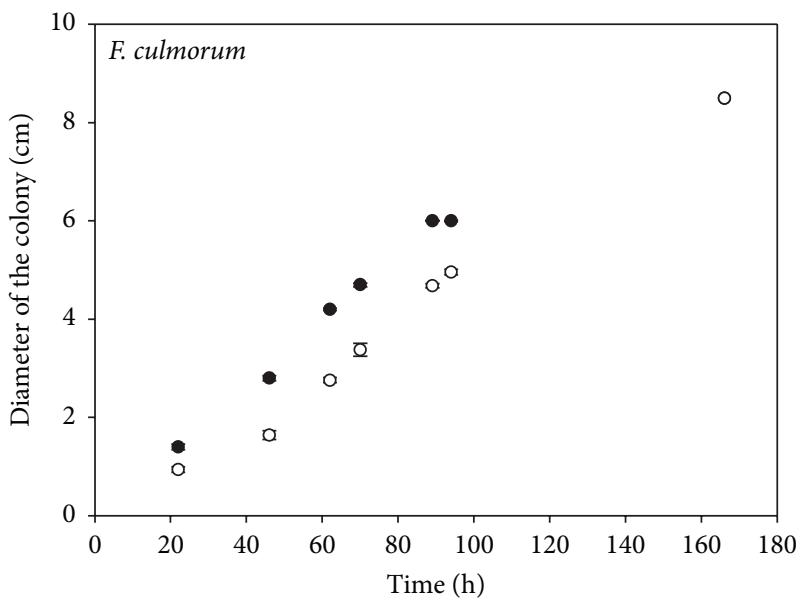

- Diameter of the colony

o Diameter of the colony in presence of supernatant

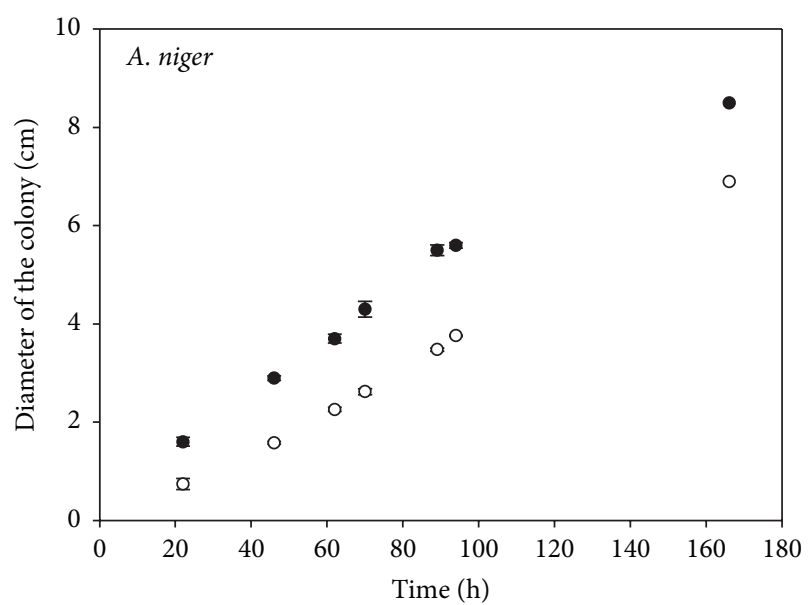

- Diameter of the colony

- Diameter of the colony in presence of supernatant

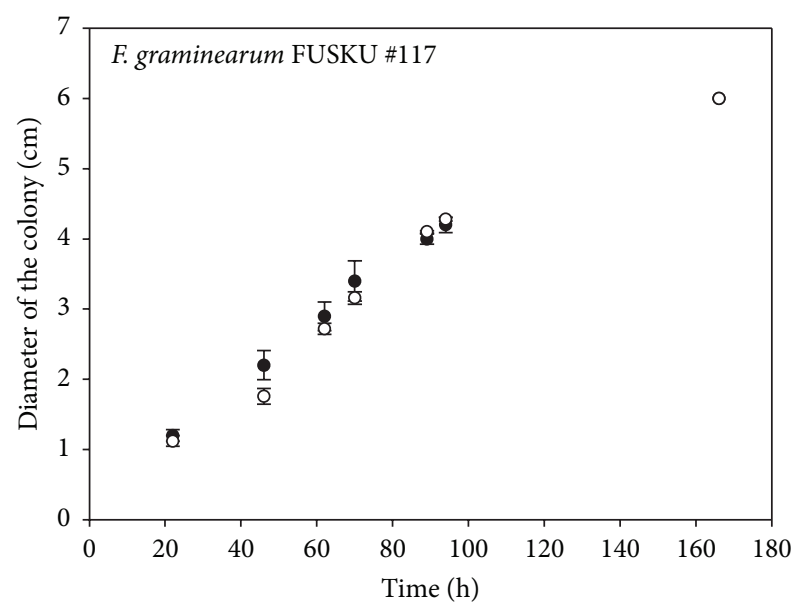

- Diameter of the colony

- Diameter of the colony in presence of supernatant

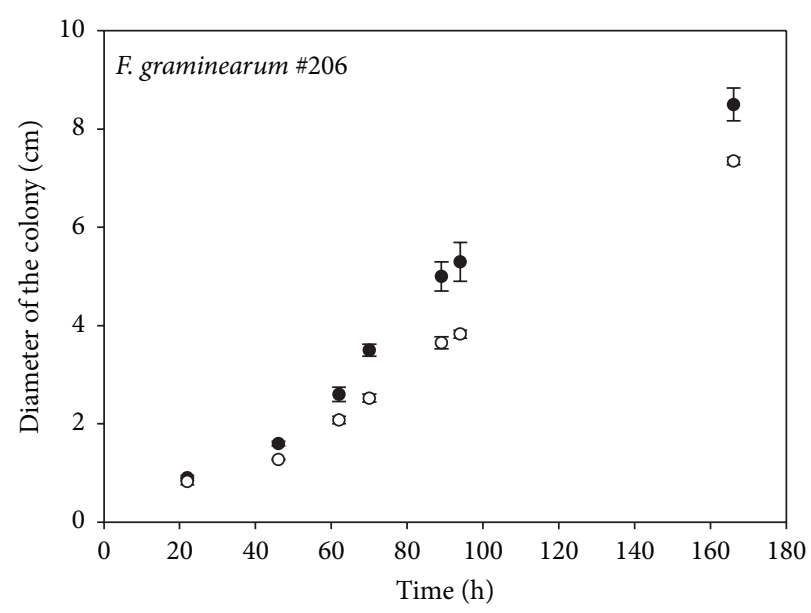

- Diameter of the colony

- Diameter of the colony in presence of supernatant

Figure 4: Growth rate of A. alternata, A. niger, F. culmorum, F. graminearum FUSKU \#117, and F. graminearum \#206 in absence (•) and presence of the supernatant $(\circ)$ represented as diameter of the colony $(\mathrm{cm})$ versus time $(\mathrm{h})$. Results represent the means of five experiments, and bars indicate \pm standard deviation. 


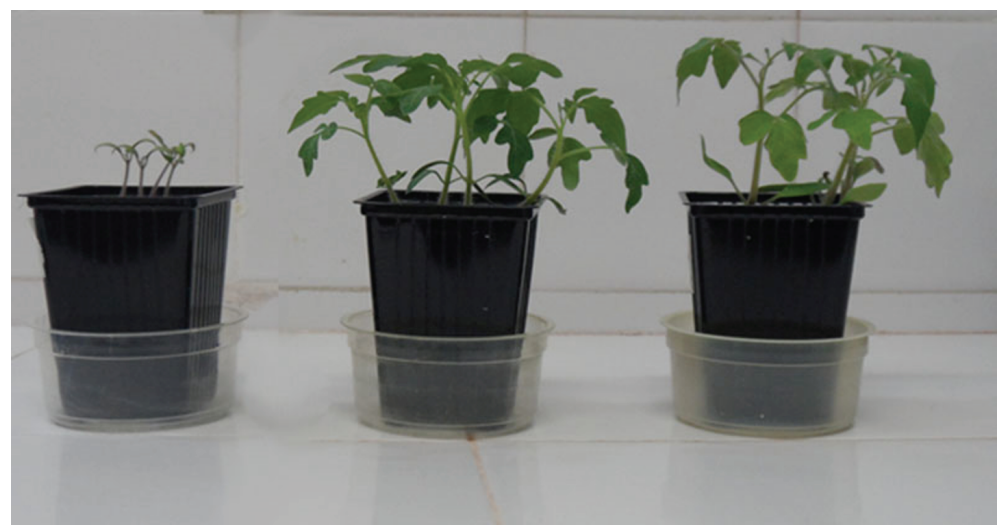

(a)

(b)

(c)

FIGURE 5: Tomato plants after 15 days of first irrigation. From right to left: (a) water, (b) P. lilacinum hydrolysate, and (c) Fähraeus solution.

TABLE 4: Effect of culture supernatant on seed germination. Results are expressed as mean $\pm \mathrm{SD} ; n=300$ ( $n$ : number of seeds tested for each treatment).

\begin{tabular}{lcc}
\hline & Control (\%) & $\begin{array}{c}\text { Treatment with } \\
\text { hydrolysate }(\%)\end{array}$ \\
\hline 48 h of incubation & $71.3 \pm 4.7$ & $84.7 \pm 3.5$ \\
72 h of incubation & $79.0 \pm 1,0$ & $86.7 \pm 2.1$ \\
\hline
\end{tabular}

cell-free culture filtrates of $T$. viride on different common fungal pathogens, controlling the growth of $R$. solani, S. rolfsii, Macrophomina phaseolina, and Colletotrichum capsici but neither A. alternata nor Pythium aphanidermatum.

The antifungal activity of $P$. lilacinum's culture supernatant against phytopathogenic fungi could be attributed to the presence of several hydrolytic enzymes as well as ammonia in the supernatant. The role of ammonia in biocontrol has been described by Pavlica et al. [43]: ammonia is the only gas present in sufficient concentrations in soil to inhibit soil fungi. Although Pavlica et al. [43], Kim et al. [44], and Mishra et al. [42] worked with culture filtrates, none of them measured cell wall-degrading enzymes that could be present in those filtrates. Chang et al. [22] reported that culture supernatant of B. cereus QQ308 grown on shellfish chitin wastes exhibited a similar enzymatic activities profile with hydrolyzing activity against chitin, casein, and glycol chitosan and is capable of inhibiting the growth of several soil-borne fungal plant pathogens including F. oxysporum, R. solani, and P. ultimum.

\subsection{In Vivo Plant Growth-Promoting Activity of Cell-Free Supernatant}

3.2.1. Effect of Culture Supernatant on Tomato Seed Germination and Tomato Plant Growth. The effect of P. lilacinum's supernatant on tomato seed germination is shown in Table 4. After $48 \mathrm{~h}$ of incubation, seed germination increased from $71.3 \pm 4.7$ to $84.7 \pm 2.1 \%$ when the seeds were treated with the supernatant. Similar increase was observed by Sivakumar et al. [45] using feather hydrolysates (from 42.1 to $54.8 \%$ ).

Tomato plant growth promotion was studied using a $21-$ day plant growth assay. Water and Fähraeus solution (supplemented with nitrogen) were used as control. In terms of fresh root and shoot weights, it can be seen that cell-free supernatant showed similar effect as that of the reference fertilizer on the growth of tomato plants (Figure 5 and Table 5) $(p>0.05)$.

Similar results were reported by Kim et al. [44] and Esfahani and Pour [34]. Both authors report an improvement in growth of plants when they compared their keratin hydrolysates with reference fertilizers.

\section{Conclusion}

Current trends in agriculture are focused on the reduction of the use of synthetic pesticides and inorganic fertilizers, forcing the search of alternative ways to improve a more sustainable agriculture. It was previously reported that $P$. lilacinum can grow and degrade a recalcitrant waste producing a crude extract with proteolytic activity. In this work, features dealing with plant growth-promoting activity were investigated. Functional traits such as IAA and hydrolytic enzymes production, a broad-spectrum antifungal activity and ammonification, may give to this microorganism and its cell-free supernatant a potential application as biostimulant and biocontrol agent as well as biofertilizer. To our knowledge these characteristics of $P$. lilacinum have not been described previously.

\section{Conflict of Interests}

Sebastián F. Cavalitto and Ivana A. Cavello are members of the Research Career of CONICET. Juan M. Crespo and Sabrina S. García hold a doctoral fellowship of CONICET, María F. Luna is member of the Research Career of CIC-PBA, and José M. Zapiola works at Instituto de Microbiología y Zoología Agrícola, INTA-Castelar. 
TABLE 5: Effect of culture supernatant of P. lilacinum LPSC \#876 on tomato seedling growth.

\begin{tabular}{lccc}
\hline Growth parameters & Water & Hair hydrolysate & Fähraeus solution \\
\hline Above-ground vegetation dry weight $(\mathrm{g})$ & $0.0218 \pm 0.002$ & $0.3927 \pm 0.053$ & $0.4182 \pm 0.036$ \\
Root dry weight $(\mathrm{g})$ & $0.0282 \pm 0.002$ & $0.2093 \pm 0.036$ & $0.1879 \pm 0.022$ \\
\hline
\end{tabular}

\section{Acknowledgments}

This research work was supported by CONICET. The authors would like to thank Carlos Gallegos and Marilin Galar for helping with lab experiments.

\section{References}

[1] B. C. Galarza, M. L. Garro, I. A. Cavello, M. C. Cazau, R. A. Hours, and C. S. Cantera, "Fungal biotransformation of bovine hair: assessment of structural changes," Journal of the Society of Leather Technologies and Chemists, vol. 91, no. 6, pp. 229-232, 2007.

[2] I. A. Cavello, R. A. Hours, and S. F. Cavalitto, "Bioprocessing of 'Hair Waste' by Paecilomyces lilacinus as a source of a bleachstable, alkaline, and thermostable keratinase with potential application as a laundry detergent additive: characterization and wash performance analysis," Biotechnology Research International, vol. 2012, Article ID 369308, 12 pages, 2012.

[3] N. M. R. Da Gioppo, F. G. Moreira-Gasparin, A. M. Costa, A. M. Alexandrino, C. G. M. De Souza, and R. M. Peralta, "Influence of the carbon and nitrogen sources on keratinase production by Myrothecium verrucaria in submerged and solid state cultures," Journal of Industrial Microbiology \& Biotechnology, vol. 36, no. 5, pp. 705-711, 2009.

[4] A. Haddar, A. Sellami-Kamoun, N. Fakhfakh-Zouari, N. Hmidet, and M. Nasri, "Characterization of detergent stable and feather degrading serine proteases from Bacillus mojavensis A21," Biochemical Engineering Journal, vol. 51, no. 1-2, pp. 5363, 2010.

[5] I. A. Cavello, R. A. Hours, and S. F. Cavalitto, "Enzymatic hydrolysis of gelatin layers of X-ray films and release of silver particles using keratinolytic serine proteases from Purpureocillium lilacinum LPS \# 876," Journal of Microbiology and Biotechnology, vol. 23, no. 8, pp. 1133-1139, 2013.

[6] A. Hadas and L. Kautsky, "Feather meal, a semi-slow-release nitrogen fertilizer for organic farming," Fertilizer Research, vol. 38, no. 2, pp. 165-170, 1994.

[7] A. Brandelli, "Bacterial keratinases: useful enzymes for bioprocessing agroindustrial wastes and beyond," Food and Bioprocess Technology, vol. 1, no. 2, pp. 105-116, 2008.

[8] J.-H. Jeong, Y.-D. Jeon, O.-M. Lee et al., "Characterization of a multifunctional feather-degrading Bacillus subtilis isolated from forest soil," Biodegradation, vol. 21, no. 6, pp. 1029-1040, 2010.

[9] T. Paul, S. K. Halder, A. Das et al., "Exploitation of chicken feather waste as a plant growth promoting agent using keratinase producing novel isolate Paenibacillus woosongensis TKB2," Biocatalysis and Agricultural Biotechnology, vol. 2, no. 1, pp. 5057, 2013.

[10] J.-H. Jeong, O.-M. Lee, Y.-D. Jeon et al., "Production of keratinolytic enzyme by a newly isolated feather-degrading Stenotrophomonas maltophilia that produces plant growth-promoting activity," Process Biochemistry, vol. 45, no. 10, pp. 1738$1745,2010$.
[11] C. Gortari, M. C. Cazau, and R. Hours, "Hongos nematófagos de huevos de Toxocara canis en un paseo público de La Plata, Argentina," Revista Iberoamericana de Micología, vol. 24, no. 1, pp. 24-28, 2007.

[12] I. A. Cavello, M. Chesini, R. A. Hours, and S. F. Cavalitto, "Study of the production of alkaline keratinases in submerged cultures as an alternative for solid waste treatment generated in leather technology," Journal of Microbiology and Biotechnology, vol. 23, no. 7, pp. 1004-1014, 2013.

[13] I. A. Cavello and S. F. Cavalitto, "Optimization of keratinolytic protease production by Purpureocillium lilacinum LPS \# 876 as a sustainable management of tannery hair waste," Journal of the American Leather Chemists Association, vol. 108, no. 8, pp. 300310, 2013.

[14] E. Glickmann and Y. Dessaux, "A critical examination of the specificity of the Salkowski reagent for indolic compounds produced by phytopathogenic bacteria," Applied and Environmental Microbiology, vol. 61, no. 2, pp. 793-796, 1995.

[15] A. L. Chaney and E. P. Marbach, "Modified reagents for determination of urea and ammonia," Clinical Chemistry, vol. 8, no. 2, pp. 130-132, 1961.

[16] H. P. Gajera and D. N. Vakharia, "Production of lytic enzymes by Trichoderma isolates during in vitro antagonism with Aspergillus niger, the causal agent of collar rot of peanut," Brazilian Journal of Microbiology, vol. 43, no. 1, pp. 43-52, 2012.

[17] M. Nelson, "A photometric adaptation of the Somogyi method for the determination of glucose," The Journal of Biological Chemistry, vol. 153, no. 275-280, 1944.

[18] M. Somogyi, "Notes on sugar determination," The Journal of Biological Chemistry, vol. 195, no. 1, pp. 19-23, 1952.

[19] A. Bruce, U. Srinivasan, H. J. Staines, and T. L. Highley, "Chitinase and laminarinase production in liquid culture by Trichoderma spp. and their role in biocontrol of wood decay fungi," International Biodeterioration \& Biodegradation, vol. 35, no. 4, pp. 337-353, 1995.

[20] W. Haggag, A. Kansoh, and A. M. Aly, "Proteases from Talaromyces flavus and Trichoderma harzianum: purification, characterization and antifungal activity against brown spot disease on Faba bean," Plant Pathology, vol. 15, no. 4, pp. 231-239, 2006.

[21] S.-L. Wang, W.-J. Hsiao, and W.-T. Chang, "Purification and characterization of an antimicrobial chitinase extracellularly produced by Monascus purpureus CCRC31499 in a shrimp and crab shell powder medium," Journal of Agricultural and Food Chemistry, vol. 50, no. 8, pp. 2249-2255, 2002.

[22] W.-T. Chang, Y.-C. Chen, and C.-L. Jao, "Antifungal activity and enhancement of plant growth by Bacillus cereus grown on shellfish chitin wastes," Bioresource Technology, vol. 98, no. 6, pp. 1224-1230, 2007.

[23] M. Rajkumar and H. Freitas, "Effects of inoculation of plantgrowth promoting bacteria on $\mathrm{Ni}$ uptake by Indian mustard," Bioresource Technology, vol. 99, no. 9, pp. 3491-3498, 2008.

[24] A. A. Onifade, N. A. Al-Sane, A. A. Al-Musallam, and S. AlZarban, "A review: potentials for biotechnological applications of keratin-degrading microorganisms and their enzymes for 
nutritional improvement of feathers and other keratins as livestock feed resources," Bioresource Technology, vol. 66, no. 1, pp. 1-11, 1998.

[25] M. Shoebitz, C. M. Ribaudo, M. A. Pardo, M. L. Cantore, L. Ciampi, and J. A. Curá, "Plant growth promoting properties of a strain of Enterobacter ludwigii isolated from Lolium perenne rhizosphere," Soil Biology and Biochemistry, vol. 41, no. 9, pp. 1768-1774, 2009.

[26] C. L. Patten and B. R. Glick, "Role of Pseudomonas putida indoleacetic acid in development of the host plant root system," Applied and Environmental Microbiology, vol. 68, no. 8, pp. 3795-3801, 2002.

[27] S. C. Gupta, T. D. Leathers, and D. T. Wicklow, "Hydrolytic enzymes secreted by Paecilomyces lilacinus cultured on sclerotia of Aspergillus flavus," Applied Microbiology and Biotechnology, vol. 39, no. 1, pp. 99-103, 1993.

[28] A. Khan, K. Williams, and H. Nevalainen, "Testing the nematophagous biological control strain Paecilomyces lilacinus 251 for paecilotoxin production," FEMS Microbiology Letters, vol. 227, no. 1, pp. 107-111, 2003.

[29] I. A. Cavello, R. A. Hours, N. L. Rojas, and S. F. Cavalitto, "Purification and characterization of a keratinolytic serine protease from Purpureocillium lilacinum LPS \# 876," Process Biochemistry, vol. 48, no. 5-6, pp. 972-978, 2013.

[30] S. W. Budi, D. van Tuinen, C. Arnould et al., "Hydrolytic enzyme activity of Paenibacillus sp. strain B2 and effects of the antagonistic bacterium on cell integrity of two soil-borne pathogenic fungi," Applied Soil Ecology, vol. 15, no. 2, pp. 191199, 2000.

[31] H. P. Gajera, R. M. Bambharolia, S. V. Patel, M. K. Mandavia, and B. A. Golakiya, "Significance of lytic enzymes from Trichoderma in the in vitro biocontrol of fungal plant pathogen Fusarium oxysporum f. sp. Ciceri," Indian Journal of Agricultural Biochemistry, vol. 22, no. 1, pp. 31-37, 2009.

[32] E. I. Jonhatan, R. Arulmozhiyan, S. Muthusamy, and W. W. Manuel, "Field application of Paecilomyces lilacinus for the control of Meloidogyne incognita of betelvine, Piper betle," Nematología Mediterranea, vol. 28, no. 2, pp. 131-133, 2000.

[33] D. Brand, S. Roussos, A. Pandey, P. C. Zilioli, J. Pohl, and C. R. Soccol, "Development of a bionematicide with Paecilomyces lilacinus to control Meloidogyne incognita," Applied Biochemistry and Biotechnology, vol. 118, no. 1-3, pp. 81-88, 2004.

[34] M. N. Esfahani and B. A. Pour, "The effects of Paecilomyces lilacinus on the pathogenesis of Meloidogyne javanica and tomato plant growth parameters," Iran Agricultural Reseacrh, vol. 24-25, no. 1-2, pp. 67-76, 2006.

[35] A. Khan, K. L. Williams, and H. K. M. Nevalainen, "Infection of plant-parasitic nematodes by Paecilomyces lilacinus and Monacrosporium lysipagum," Biocontrol, vol. 51, no. 5, pp. 659-678, 2006.

[36] A. R. Mendoza, R. A. Sikora, and S. Kiewnick, "Influence of Paecilomyces lilacinus strain 251 on the biological control of the burrowing nematode Radopholus similis in banana," Nematropica, vol. 37, no. 2, pp. 203-213, 2007.

[37] S. A. Waters and K. R. Barker, "Efficacy of Paecilomyces lilacinus in suppressing Rotylenchulus reniformis on tomato," Journal of Nematology, vol. 26, no. 4, pp. 600-605, 1994.

[38] C. L. Porter, "Concerning the characters of certain fungi as exhibited by their growth in the presence of other fungi," American Journal of Botany, vol. 11, no. 3, pp. 168-188, 1924.

[39] M. Fenice, L. Selbmann, R. Di Giambattista, and F. Federici, "Chitinolytic activity at low temperature of an Antarctic strain
(A3) of Verticillium lecanii," Research in Microbiology, vol. 149, no. 4, pp. 289-300, 1998.

[40] M. Stefanova, A. Leiva, L. Larrinaga, and M. F. Coronado, "Metabolic activity of Trichoderma spp. isolates for a control of soilborne phytopathogenic fungi," Revista Facultad de Agronomía, vol. 16, pp. 509-516, 1999.

[41] A. Gousterova, M. Nustorova, D. Paskaleva, M. Naydenov, G. Neshev, and E. Vasileva-Tonkova, "Assessment of feather hydrolysate from thermophilic actinomycetes for soil amendment and biological control application," International Journal of Environmental Research, vol. 6, no. 2, pp. 467-474, 2012.

[42] B. K. Mishra, R. K. Mishra, R. C. Mishra et al., "Biocontrol efficacy of Trichoderma viride isolates against fungal plant pathogens causing disease in Vigna radiata L," Archives of Applied Science Research, vol. 3, no. 2, pp. 361-369, 2011.

[43] D. A. Pavlica, T. I. Hora, J. J. Bradshaw, and et al, "Volatiles from soil influencing activities of soil fungi," Phytopathology, vol. 14, pp. 758-765, 1978.

[44] J. M. Kim, Y. M. Choi, and H. J. Suh, "Preparation of feather digests as fertilizer with Bacillus pumilis KHS-1," Journal of Microbiology and Biotechnology, vol. 15, no. 3, pp. 472-476, 2005.

[45] T. Sivakumar, T. Shankar, P. Vijayabaskar, and V. Ramasubramanian, "Plant growth promoting activity of nickel tolerant Bacillus cereus TS1," Journal of Agricultural Technology, vol. 8, no. 6, pp. 2101-2113, 2012.

[46] L. E. Fuentes-Ramirez, T. Jimenez-Salgado, I. R. AbarcaOcampo, and J. Caballero-Mellado, "Acetobacter diazotrophicus, an indoleacetic acid producing bacterium isolated from sugarcane cultivars of México," Plant and Soil, vol. 154, no. 2, pp. 145-150, 1993.

[47] J. L. Hernández-Mendoza, J. D. Quiroz-Velásquez, V. R. Moreno-Medina et al., "Biosynthesis of anthranilic and indolacetic acids from trypthophan by one Azospirillum brasilense strain native from Tamaulipas, México," Avances en Investigación Agropecuaria, vol. 12, no. 1, pp. 57-67, 2008.

[48] A. J. Rodríguez Cheang, I. D. Trujillo Cerón, Y. F. Bringas et al., "Physiological characterization of sugarcane's endophytic microbial community," Revista Colombiana de Biotecnología, vol. 7, no. 1, pp. 66-75, 2005.

[49] A. Karnwal, "Production of indole acetic acid by fluorescent Pseudomonas in the presence of L-tryptophan and rice root exudates," Journal of Plant Pathology, vol. 91, no. 1, pp. 61-63, 2009.

[50] N. B. Patil, M. Gajbhiye, S. Ahiwale, A. B. Gunjal, and P. Balasaheb, "Optimization of Indole 3-acetic acid (IAA) production by Acetobacter diazotrophicus L1 isolated from sugarcane," International Journal of Environmental Sciences, vol. 2, no. 1, pp. 295-302, 2011. 

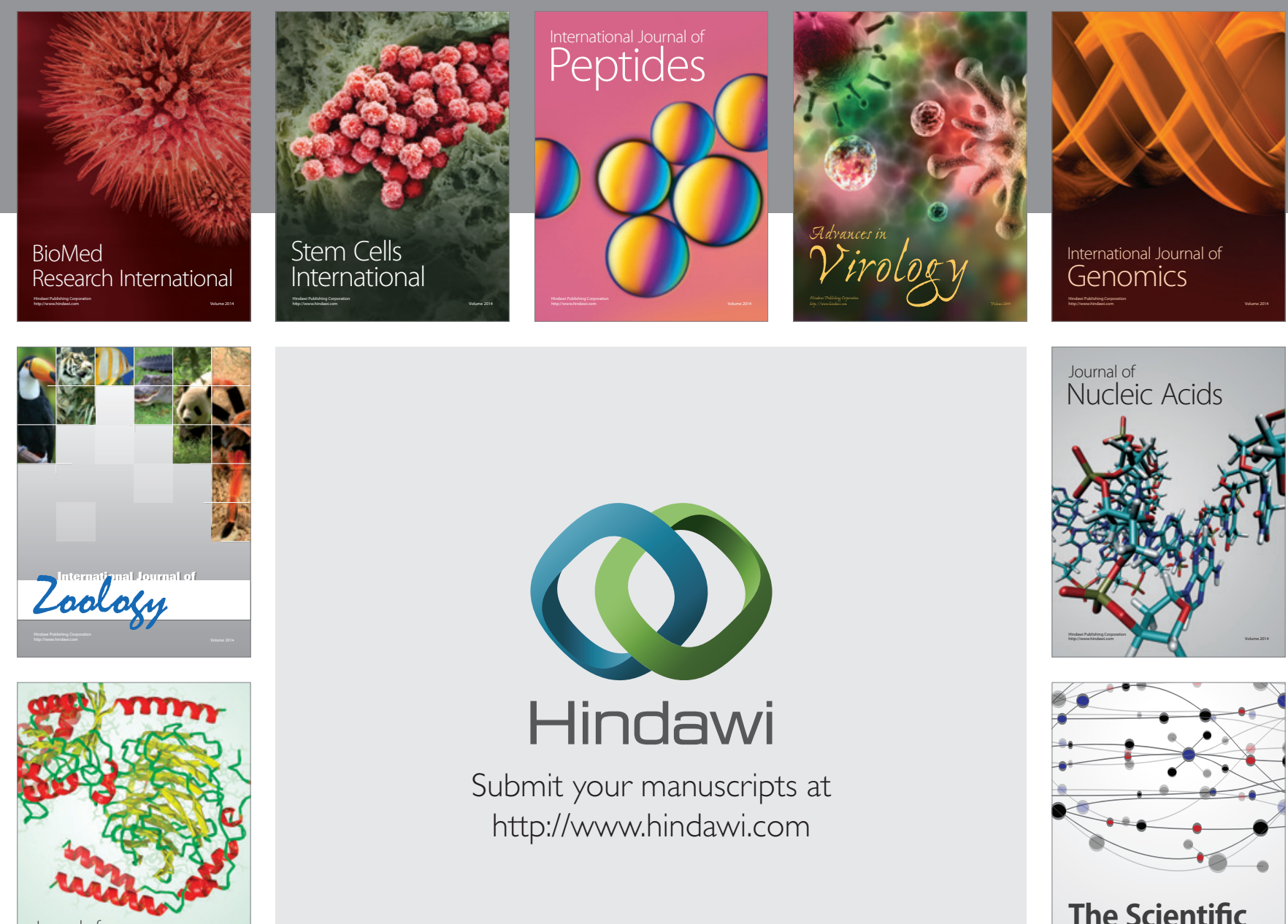

Submit your manuscripts at

http://www.hindawi.com

Journal of
Signal Transduction
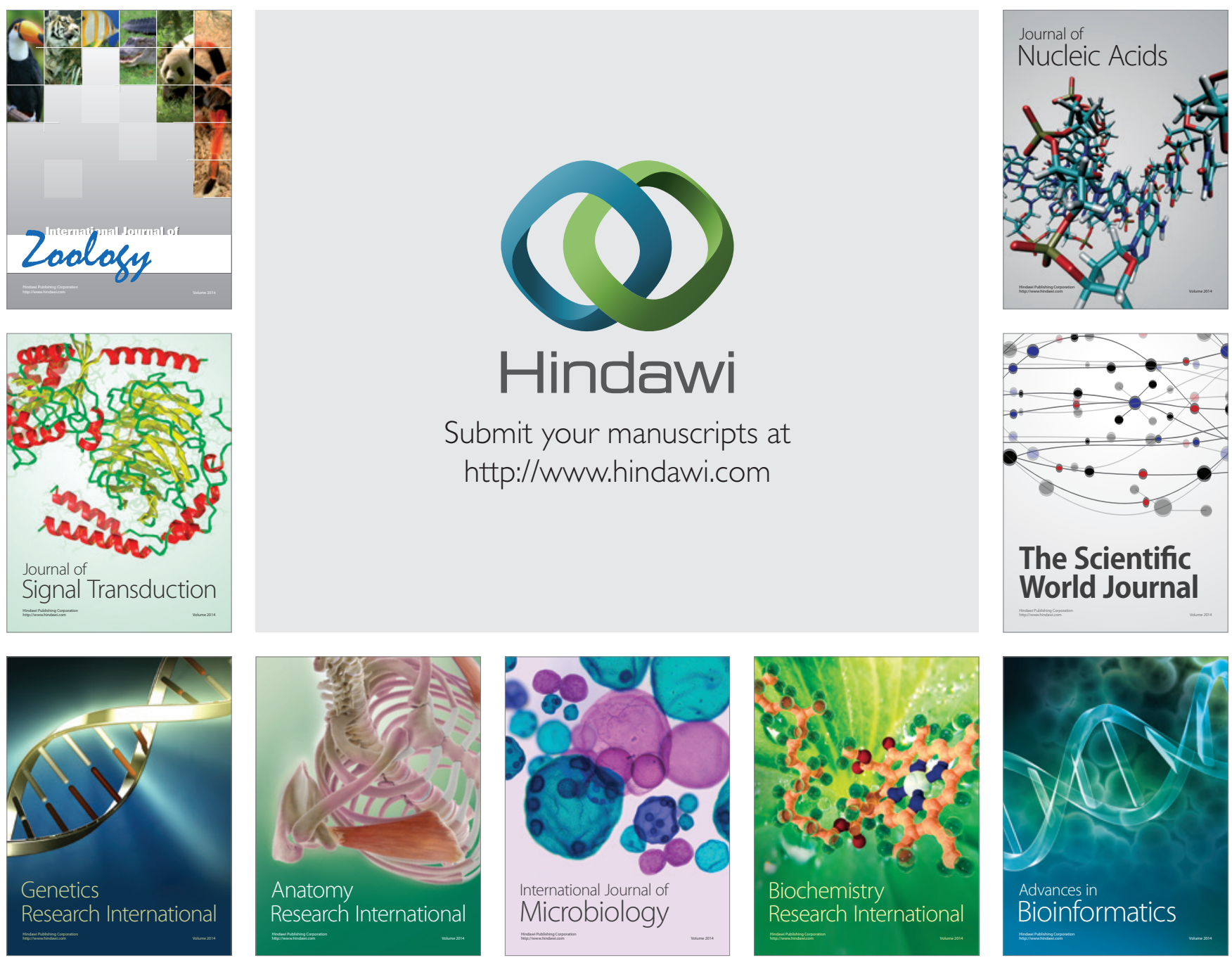

The Scientific World Journal
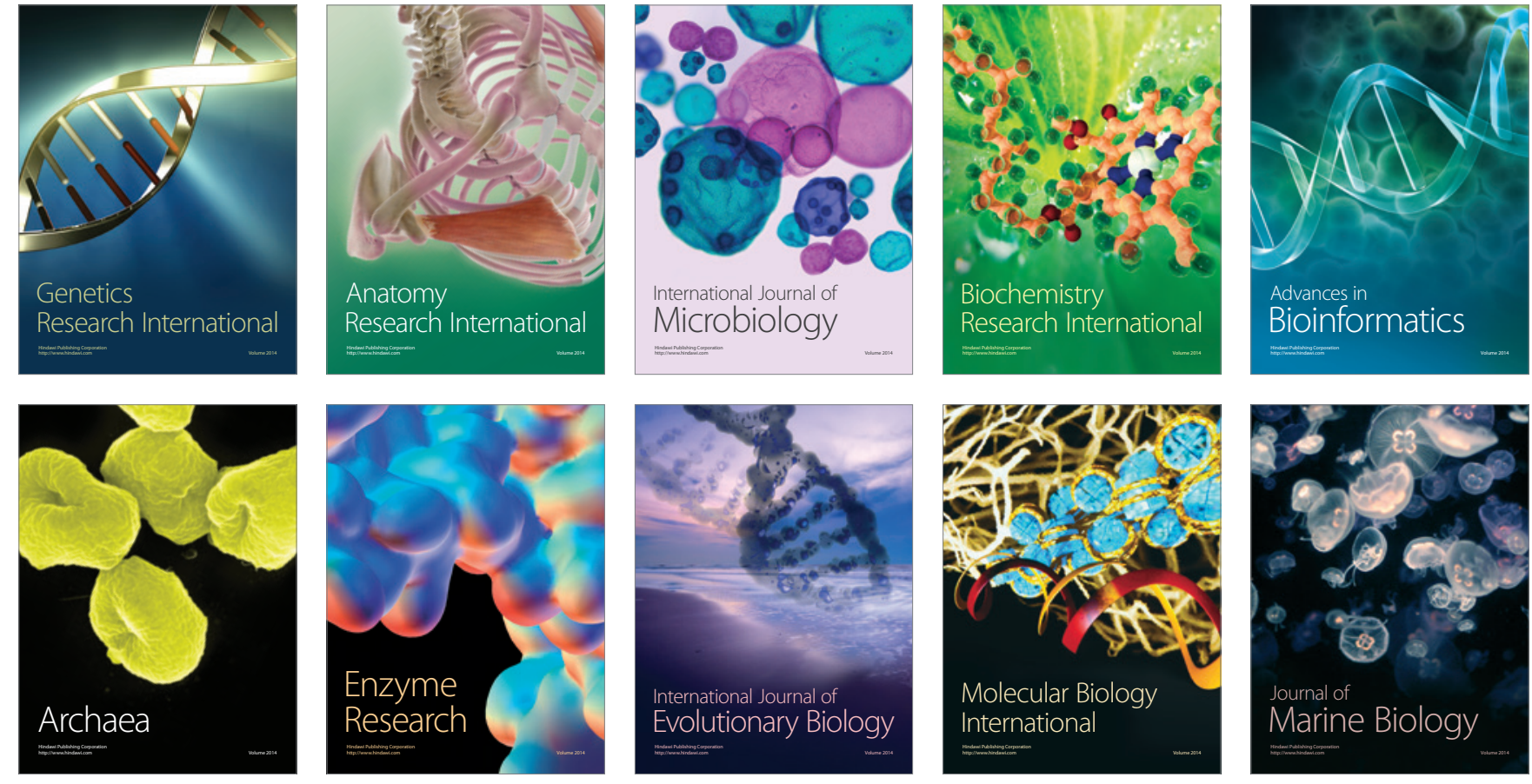